\title{
Frontières
}

\section{La marge}

\section{Entre agonies et extases}

\section{Diane Laflamme}

Volume 14, numéro 1, automne 2001

Où est la marge ?

URI : https://id.erudit.org/iderudit/1074142ar

DOI : https://doi.org/10.7202/1074142ar

Aller au sommaire du numéro

\section{Éditeur(s)}

Université du Québec à Montréal

ISSN

1180-3479 (imprimé)

1916-0976 (numérique)

Découvrir la revue

Citer ce document

Diane (2001). La marge : entre agonies et extases. Frontières, 14(1), 3-4.

https://doi.org/10.7202/1074142ar

Ce document est protégé par la loi sur le droit d'auteur. L'utilisation des services d'Érudit (y compris la reproduction) est assujettie à sa politique d'utilisation que vous pouvez consulter en ligne.

https://apropos.erudit.org/fr/usagers/politique-dutilisation/
Cet article est diffusé et préservé par Érudit.

Érudit est un consortium interuniversitaire sans but lucratif composé de l’Université de Montréal, l'Université Laval et l'Université du Québec à Montréal. Il a pour mission la promotion et la valorisation de la recherche. https://www.erudit.org/fr/ 


\section{LA MARGE \\ ENTRE AGONIES ET EXTASES}

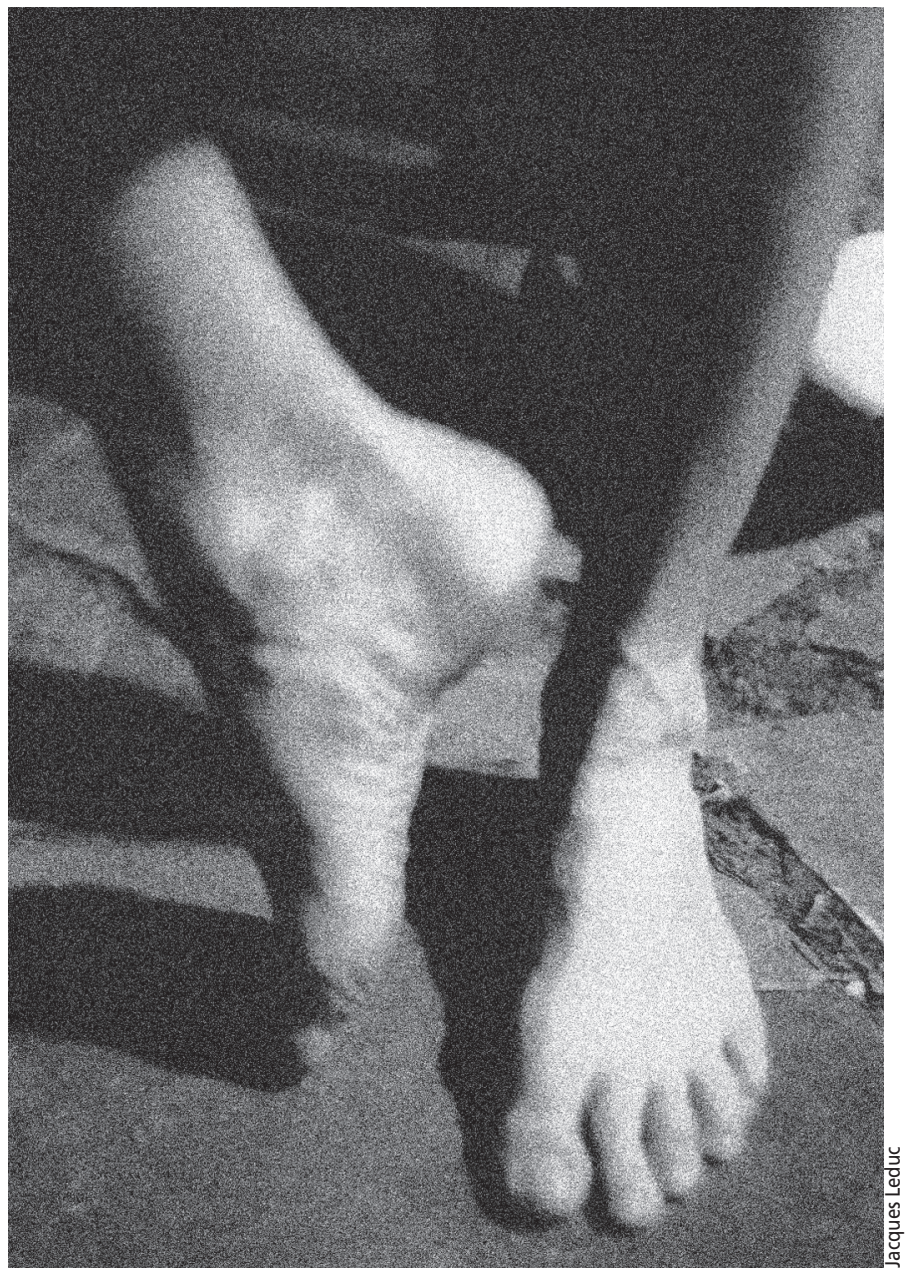

Diane Laflamme, Ph.D. Rédactrice en chef.

Les groupes humains s'inscrivent dans de vastes mouvances, à l'échelle de toute la Terre, planète bleue dont nous savons l'émouvante beauté maintenant que des yeux humains ont su nous la décrire de l'espace. Le reste du groupe est resté au sol. C'est dans un quotidien plus banal, avec ses propres pas (le groupe étant dépourvu de pieds), qu'une personne avance et qu'elle trace ses chemins dans les espaces qu'elle choisit d'habiter. Il y a des gens qui dansent sur des musiques qui sont une création de leur époque ou dont ils ont hérité, d'autres qui avancent au pas sur des marches militaires, d'autres aussi qui se gèlent les orteils dans des endroits sordides malgré leurs espadrilles aux formes aérodynamiques et la hauteur de leurs talons, en marge de l'ordre et du confort des sociétés opulentes.
La marge fait parfois la une des journaux. C'est souvent à l'occasion d'un événement artistique salué à grands renforts d'adjectifs qui se veulent conciliants à l'égard de ceux et celles qui choisissent de se démarquer avec panache de la mouvance du reste du groupe. On en parle aussi volontiers pour dénoncer le problème que posent les marginaux en paysage urbain : artistes de graffitis, sans-abri, etc. Ainsi, à Montréal, un maire nouvellement élu a commencé en toute bonne volonté sans doute à se promener dans sa nouvelle ville... et il y a découvert des personnes endormies sur l'asphalte gelée par l'hiver. Quelques jours plus tard, à la suite d'une réunion extraordinaire de certains membres de son comité exécutif, il a entre autres déclaré aux journalistes : "On va essayer de regrouper les intervenants pour qu'il y ait une meilleure concertation et que l'on puisse dire aux gens qui sont dans la rue: "Ce n'est peut-être pas de votre faute, peut-être voulez-vous continuer comme ça mais, nous, 
en tant que société, on ne peut pas accepter que dans notre ville on ait des personnes qui ne font pas les efforts nécessaires pour s'intégrer"1 ». À Paris, un diplômé en philosophie, docteur en anthropologie, membre de la Société psychanalytique de Paris et chercheur à la maison des sciences de l'Homme a attiré l'attention des médias en publiant l'automne dernier, après quinze années passées auprès des clochards, un livre intitulé Les Naufragés ${ }^{2}$; il est même arrivé à Patrick Declerck de revêtir «des habits de mendiant pour se faire ramasser par la police et dormir incognito dans les refuges $^{3}$ ». Il déclare en entrevue : «Être clochard, c'est une manière spécifique d'organiser son rapport au monde. C'est une folie particulière. [...] Ce sont des gens du négatif qui vivent au plus près de la mort, des morts-vivants. Comme tous les fous, ils posent la question du non-sens, du caractère invivable de la vie ${ }^{4} »$. Notre maire, son conseil exécutif, nous toutes et tous qui croisons dans nos rues ces sans-abri, oserons-nous reconnaître qu'ils ont raison : oui, à bien des égards, la vie est invivable. Qu'avons-nous vraiment à leur proposer? L'intégration à quoi ? À nos piteux aménagements, luxueux mais essentiellement fondés sur le chacun pour soi... en attendant que ça passe?

La question est immense. Il est plus facile de se faire dire que la vie est invivable par un poète, si possible d'un autre siècle et d'une autre ville, que par un itinérant ou un mendiant qui boit le même alcool que nous et qui en abuse. Oui, il faut que nos élites s'indignent et convoquent des réunions d'urgence. Oui, j'espère que les lecteurs de Frontières parcourront avidement ce numéro que nous leur proposons sur le thème de la marge. Oui, il faut que nous nous parlions de ce que nous savons faire, ensemble, même lorsque la vie est invivable... parce que la vie est invivable. Il y a parfois des extases qui nous ravissent, des transports passionnés qui nous décentrent, des respirations qui goûtent le simple bonheur d'être en vie. Osons aussi les dire; ils nous rapprochent de celles et de ceux qui s'accrochent à des extases qui les tuent à répétition.

Les personnes qui ont collaboré à ce numéro présentent des recherches, des réflexions et des expériences qui se rattachent à la marginalité et / ou à l'exclusion. Plusieurs abordent plus précisément des problèmes reliés à l'itinérance, la toxicomanie, les conduites à risque, la prostitution, l'appauvrissement, le racisme, les handicaps physiques ou mentaux... Toutes font référence à quelque chose que nous nous savons impuissants à nier: le mal de vivre.
Nous chantons, nous dansons, nous célébrons la vie opulente, certes, mais nous savons fort bien que nous marchons sur une corde raide. Le tragique de la vie nous rattrape parfois brusquement et nous «désintègre »... pour une minute, des heures, des mois. Il y a aussi tout ce qui nous taraude plus insidieusement: par exemple, notre vie invivable au travail, dans des bureaux où règnent justement des spécialistes de l'intégration!

Un heureux concours de circonstances nous permet ici de donner la parole à des jeunes de quatrième secondaire de l'École la Montée, pavillon Le Ber, dans l'Estrie. Après avoir visionné le film Tu as crié LET ME GO» de Anne Claire Poirier, ils ont adressé à la cinéaste un recueil de textes écrits dans le cadre de leur cours de français. Dans des encadrés semés au fil des pages, nous vous proposons quelques extraits de ces textes sur des thèmes comme la rue, la drogue, la prostitution et l'autorité parentale. Nous remercions ces jeunes de se joindre ainsi à la conversation.

Dans notre corps à corps avec la vie, il $\mathrm{y}$ a des agonies et des extases. Quel âge avions-nous lorsque nous l'avons découvert ? Il y eut des jours, il y eut des matins... après combien de blessures et de rebuffades cesse-t-on de croire à des mouvances inédites entre le centre et la marge?

1. Cité dans François Cardinal, «Les sans-logis deviennent la priorité de Tremblay», dans Le Devoir, Montréal, le mardi 8 janvier 2002, p. A 1.

2. P. Declerck (2001). Les Naufragés, Paris, Plon.

3. Christian Rioux, dans "Voyage chez les morts-vivants. Après 15 ans auprès des clochards de Paris, Patrick Declerck s'interroge sur les limites de l'humanité », Le Devoir, Montréal, le mercredi 9 janvier 2002, p. A 1 et A 8.

4. Cité dans C. Rioux, Ibid.

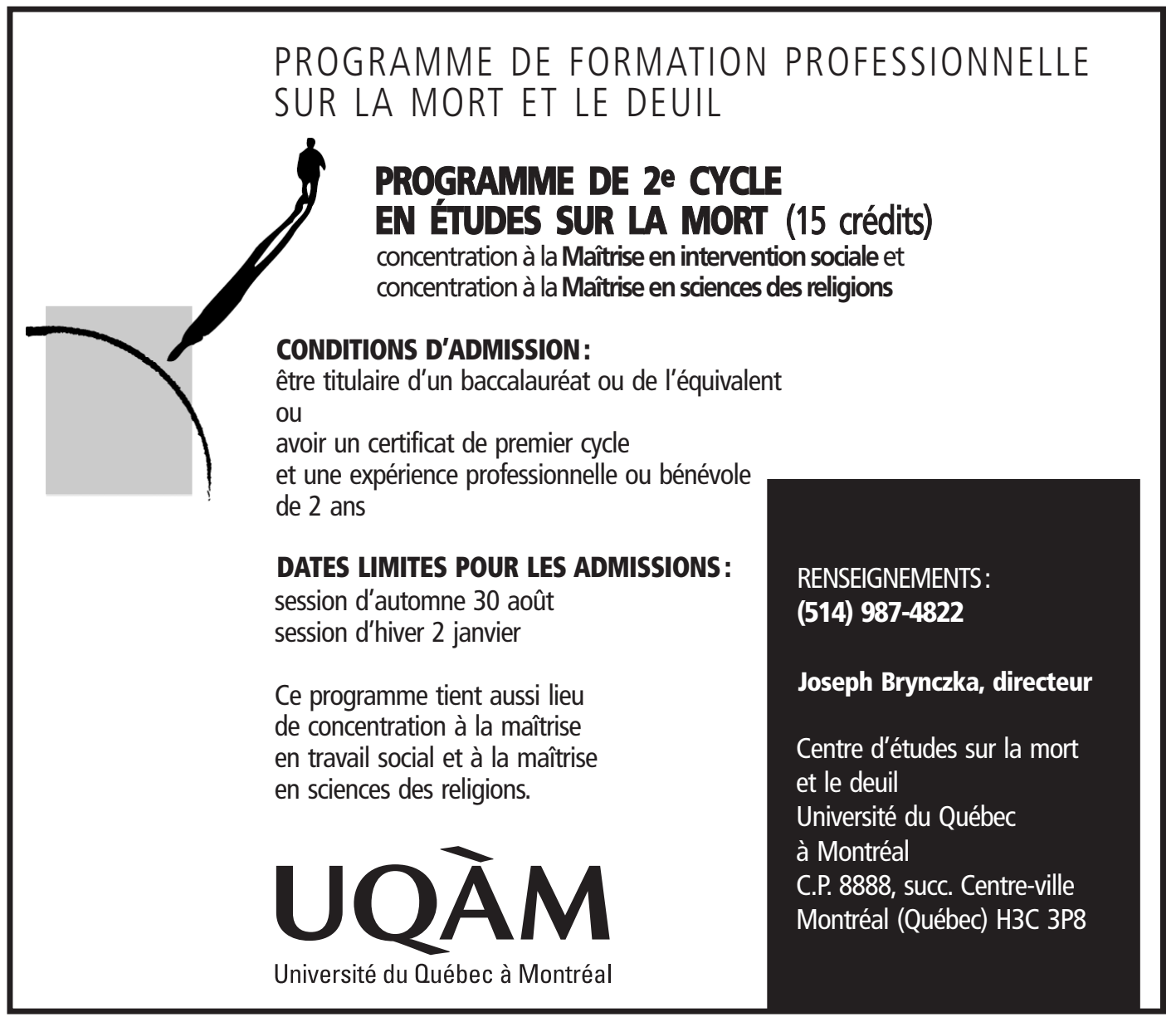

